\title{
A IDEIA DE NAÇÃO PARA A DOUTRINA DE SEGURANÇA NACIONAL NO BRASIL ${ }^{1}$
}

\section{THE CONCEPT OF NATION FOR THE NATIONAL SECURITY DOCTRINE IN BRAZIL}

Thaís Fleck Olegário²

RESUMO: O objetivo desse trabalho é apontar a concepção de nação para a Doutrina de Segurança Nacional. Na primeira parte, são analisados os aspectos constitutivos da Doutrina de Segurança Nacional no Brasil, como o alargamento do conceito de guerra e o estabelecimento do "inimigo interno". Na segunda parte, é apresentado brevemente, o exemplo do Brasil, demonstrando o processo de refundaçáo nacional após o golpe de Estado, ou seja, a retomada de elementos de um passado nacional como instrumento de legitimação do regime ditatorial.

PALAVRAS-CHAVE: Nação; Doutrina de Segurança Nacional; Brasil.

ABSTRACT: This paper aims analyze the concept of nation for the National Security Doctrine. In the first part, the constitutive aspects of the National Security Doctrine in Brazil are analyzed, such as the extension of the concept of war and establishment of the "internal enemy". In the second part, we will show the example of Brazil and the process of national refunding after the coup, this is the resumption of elements of a national past as an instrument for legitimation the dictatorship.

KEYWORDS: Nation; National Security Doctrine; Brazil.

\section{INTRODUÇÃO}

Os países do Cone Sul enfrentaram a partir da década de 1960 um longo período de ditaduras marcadas pelo terror institucionalizado. ${ }^{3} \mathrm{~A}$ historiografia recente adjetiva tais ditaduras como de segurança nacional. ${ }^{4}$ A Doutrina de Segurança Nacional (DSN), fundamento ideológico base aos regimes ditatoriais latino-americanos, foi formulada a partir dos Estados Unidos (EUA) no contexto da Guerra Fria, especialmente a partir da Doutrina Truman em 1947.

A vertente brasileira é correntemente denominada como Doutrina de Segurança Nacional e Desenvolvimento pelo binômio: segurança nacional atrelada ao desenvolvimento econômico.

2 Mestranda em História pela Universidade Federal do Rio Grande do Sul- UFRGS. Bolsista do CNPq. E-mail: fleckolegario@gmail.com

3 “O Terrorismo de Estado se fundamenta na lógica de governar mediante a intimidação. Em suma, é um sistema de governo que emprega o terror para enquadrar a sociedade e que conta com o respaldo dos setores dominantes, mostrando a vinculaçâo intrínseca entre Estado, governo e aparelho repressivo" (PADRÓS, 2005, p. 64).

4 Referimo-nos principalmente as obras Ditaduras Militares na América Latina (2004) e Cone Sul em Tempos de Ditadura (2013), obras organizadas por Cláudia Wasserman, César Guazzelli e Enrique Serra Padrós respectivamente. 
No Brasil, a Doutrina foi consolidada através da Escola Superior de Guerra (ESG), que por sua vez foi fundada em 1949 após com a assistência de consultores franceses e norte-americanos - através do National War College - (ALVES, 1984, p. 24). ${ }^{5}$ A ESG contou, desde o seu surgimento, com a participação de civis especialistas como alunos. ${ }^{6}$ Outra particularidade latino-americana foi o foco dado ao ataque "indireto" da Uniáo Soviética, que operaria através das guerras subversiva e revolucionária, este elemento foi essencial no desenvolvimento da ideia de "inimigo interno" (ALVES, 1984, p. 24). Não obstante, constituiu um elemento característico da Escola brasileira a dedicação para além da política externa e sua dedicação ao projeto que aliava um projeto de desenvolvimento econômico e segurança nacional.

Dessa forma, pode-se definir que a segurança nacional, nas linhas da DSN, fundamentava a necessidade de salvaguarda das "naçóes livres" ou ocidentais frente à ameaça comunista. Entre os pressupostos da Doutrina, a nação existia como um organismo, cuja sobrevivência estava ameaçada pela subversão. ${ }^{7}$ Nessa perspectiva a vontade nacional não era nada além que o impulso da nação personificada reduzida à lógica da guerra.

Recuando um pouco a análise, podemos destacar um movimento que precede a consolidação da Doutrina no Brasil. Tratam-se dos dois projetos de nacionalismo que disputavam os discursos sobre a nação desde finais da década de 1950. De um lado a conjunção do nacionalismo com a participação popular, que se desenvolveu a partir de dois episódios principais: "a campanha que culminou na criação da Petrobrás, [...] e a emoção desencadeada pelo suicídio de Vargas” (PÉCAUT, 1990, p. 99). Assim:

A campanha "O petróleo é nosso" propiciou a oportunidade para a convergência de diversos setores nacionalistas que se colocavam contra o projeto inicial apresentado por Vargas, por considerá-lo excessivamente moderado: a fracção do Exército liderada pelo general Estillac Leal, ministro do Exército de 1950 a 1952 e que contribuiu para criar o Centro de Estudos e Defesa do Petróleo e da Economia Nacional (CEPDEN); os comunistas; os numerosos intelectuais; membros do PTB mas também da UDN [...]. Com maior razão, o contexto no qual ocorreu o suicídio de Getúlio Vargas, em 24 de agosto de 1954, instituiu o nacionalismo como modalidade de cidadania popular (PÉCAUT, 1990, p. 100).

Como aponta Daniel Pécaut, esse tipo de nacionalismo passa a significar "ativação das massas e resistência ao imperialismo" (PÉCAUT, 1990, p. 101). Em suas fileiras agrupava a esquerda intelectual, entre os quais figuravam membros de organizaçóes como o

Cf ALVES, Maria Helena Moreira. Estado e Oposição no Brasil (1964-1984), p. 24, 1984.

6 Entretanto, como ressalva Gilvan Dockhorn não eram todos os civis que poderiam participar dos quadros da ESG, pois a "exigência de curso superior e posiçáo de destaque em sua área praticamente afastou a possibilidade de militantes sindicais, operários, camponeses e estudantes participarem da Escola” (DOCKHORN, 2002, p. 61).

7 Em outras palavras: "refletindo a lógica bipolar da Guerra Fria e as novas estratégias de dominação dos EUA sobre a América Latina, a DSN disseminou-se através das Academias e Escolas de Guerra, formando quadros especializados a partir de uma série de preceitos básicos: a lógica da bipolaridade, a delimitação de zonas de influência pelas superpotências: a satanização do inimigo; a introdução de que o Estado e a Nação são organismos vivos passíveis de contaminação pelo vírus comunista (o que, por sua vez justifica um virulento anticomunismo)" (PADRÓS, 2005, p. 184). 
Instituto Superior de Estudos Brasileiros (ISEB), os Centros de Cultura Popular (CPC), o Movimento de Educação de Base (MEB), entre outros (PÉCAUT, 1990, pp. 107-189).

De outro lado, estavam os nacionalistas simpáticos à penetração de capitais estrangeiros no país compostos por: empresariado nacional associado às multinacionais, banqueiros, comerciantes, setores ruralistas proprietários de grande porte e os tecnocratas urbanos vinculados aos interesses multinacionais formados em escolas técnicas (como o Instituto Brasileiro de Economia e a Fundação Getúlio Vargas) articulados através do Instituto Brasileiro de Ação Democrática (IBAD) e do Instituto de Pesquisas e Estudos Sociais (IPES). O IBAD foi criado em 1959 por grupos do empresariado industrial brasileiro e tinha por objetivo agir em favor da "defesa da democracia". Entretanto, pode-se apontar que tal instituição estava destinada à divulgaçáo de conteúdo anticomunista. A entidade foi fechada em 1963, durante as investigaçóes da Comissão Parlamentar de Inquérito (CPI) sobre a ilegalidade de suas ações nas eleições de 1962, através da Ação Democrática Parlamentar (ADP) e o financiamento recebido de corporaçóes estadunidenses. Neste sentido, René A. Dreifuss destaca:

\begin{abstract}
Os interesses multinacionais e associados consideraram outras formas de representação de interesses além do controle da administração paralela ou do uso de lobbying sobre o Executivo. Eles desejavam compartilhar do governo político e moldar a opiniáo pública, assim o fazendo através da criação de grupos de ação política e ideológica. O primeiro desses grupos a ter notoriedade nacional em fins da década de cinqüenta foi o IBAD - Instituto Brasileiro de Ação Democrática. (DREIFUSS, 1981, p. 102).
\end{abstract}

O IPES foi lançado um mês após a posse de João Goulart como presidente da República, como justificativa para sua criaçáo estava o "[...] interesse das classes conservadoras de inteirar-se das flutuações da realidade social, cultural, política e econômica do Brasil" (RAMOS, 1963, p. 32). Em sua composição contava com quadros da CONSULTEC; do Conselho Nacional de Economia; da Fundaçáo Getúlio Vergas; da Associaçáo Comercial; do Centro Industrial do Rio de Janeiro; do CONCLAP; da Federaçấo das Indústrias da Guanabara; das empresas do Grupo Light; da SOMBRAMIL (United States Steel); LafterKlabin; da COMAC; do grupo Guinle-Galdeano e do Banco do Estado da Guanabara (RAMOS, 1963, p. 34). ${ }^{8}$ Vale reter ainda que havia relaçôes estreitas entre o IPES/IBAD e a ESG, tendo eles compartilhado membros.

Este grupo defendia que o desenvolvimento da nação somente era possível através da derrota do comunismo, eram também favoráveis à presença do capital multinacional no Brasil, inclusive em empresas públicas. Desse modo, vinculados à DSN passaram a influir na opinião pública através de publicaçôes em jornais e revistas bem como por meio de programas de rádio.

Do ponto de vista econômico o primeiro grupo, de um nacionalismo de caráter popular e voltado à autonomia nacional, defendia o desenvolvimento através de empresas estatais e o crescimento independente do país, desse modo:

$8 \quad$ Para um levantamento minucioso sobre as atividades e componentes do IPES Cf. DREIFUSS, René Armand. 1964 A conquista do Estado: Ação Política, Poder e Golpe de Classe. Petrópolis: Vozes, 1981. 
Celso Furtado e outros economistas divulgariam no Brasil, visando a colocar o Estado a serviço de um processo acelerado de substituição de importaçóes, graças à ampliação do mercado interno e às medidas para contrabalancear a deterioraçáo nos termos de trocas. Essa teorização, porém, era inseparável a uma meta política emancipadora, segundo a qual a cidadania política deveria ampliar-se à medida que a modernização econômica promovesse a independência nacional (PÉCAUT, 1990, p. 101).

Do outro lado, convergiam dois discursos: o impetrado pelo IPES/IBAD que apresentava a necessidade de desenvolvimento baseado na entrada de capitais estrangeiros no país e aquele teorizado pela ESG em que se preconizava um tipo de capitalismo baseado na forte interferência do Estado, bem como estava incluída nessa concepção um projeto de industrialização para o Brasil. Em suma, segundo Alves, tratava-se de desenvolver setores infraestruturas - redes de comunicação, rodovias, ferrovias, entre outros -; principalmente em áreas consideradas geopoliticamente importantes como as fronteiriças, consolidando assim a integração nacional e, sobretudo, promover "uma rápida arrancada do desenvolvimento econômico, para obter o apoio da população". Contudo, "é fundamental ter em mente que, na Doutrina de Segurança Nacional, a defesa militar, mais que as necessidades materiais básicas da população, é considerada o principal objetivo do desenvolvimento econômico" (ALVES, 1984, p. 49).

Ambos os discursos foram formulados a partir de uma realidade latente: a subordinação do país a uma situação de dependência econômica. Neste sentido, Alves aponta que a situação de dependência está relacionada à capacidade de "criar novas tecnologias, de expandir o setor de bens de capital e de controlar seu sistema financeiro e bancário" (ALVES, 1984, p. 21). No caso de economias dependentes essa capacidade é subordinada a um elemento externo, a outro país, criando assim, um elo de subordinação. No entanto, Alves dispóe que a condição de dependência não implica em um subdesenvolvimento permanente, mas resulta, por outro lado, em um processo de desenvolvimento distorcido, através do qual "mantêm-se sem solução consideráveis problemas sociais como as desigualdades regionais, graves disparidades na distribuição de renda, altos índices de desemprego e níveis de vida abertamente baixos para a maioria da população" (ALVES, 1984, p. 22).

O aprofundamento do desenvolvimento de tipo dependente, ocorrido durante o período ditatorial, reflete a vitória de um dos discursos apontados: o dos nacionalistas vinculados à DSN. Portanto, o que se torna vitorioso, através do golpe de 1964 no Brasil, é o discurso de uma classe encouraçado sob a égide de vontade nacional. A passagem do discurso de interesse de um grupo ao interesse nacional se dá a partir da reformulação do próprio Estado, levada a efeito através da coerção e de uma transformação normativa. Neste sentido, a seguir faremos a análise de como se constitui no Brasil o discurso sobre a nação dentro das linhas da Doutrina de Segurança Nacional.

\section{SOBRE A DEFINIÇÃO DE NAÇÃO}

Hobsbawm evidencia que o conceito de "nação" é historicamente recente e considera, assim como Gellner, que o nacionalismo vem antes da nação e não o oposto. Outros 
pontos são destacáveis na concepção do autor: que não se deve analisar a nação a partir de uma concepçáo de sua existência dada a priori; que os fenômenos que constituem as naçóes náo podem ser reduzidos a apenas elementos culturais e sociais, devem ser considerados também: as condições econômicas, administrativas, técnicas e políticas; e que as naçóes constituem fenômenos duais - construídos pelo alto e de baixo - por isso só podem ser apreendidas através da observação não só do postulado de "ideologias oficiais de Estado e movimentos", mas, em "termos das suposiçóes, esperanças, necessidades, aspiraçóes e interesses das pessoas comuns, as quais náo são necessariamente nacionais e menos ainda nacionalistas" (HOBSBAWM, 1990, p. 19). Através da análise da transformação do significado da palavra "nação" no dicionário da Real Academia Espanhola, Hobsbawm expóe que antes do século XIX:

A palavra nación significava simplesmente "o agregado de habitantes de uma província, de um país ou de um reino" e também "um estrangeiro". Mas agora era dada como "um Estado ou corpo político que reconhece um centro supremo de governo comum", e também "o território constituído por esse Estado e seus habitantes, considerados como um todo" (HOBSBAWM, 1990, p. 27).

Assim como Hobsbawm, Anne-Marie Thiesse indica que as "identidades nacionais não existiam em 1800. Sua criação foi uma das grandes obras européias do século XIX, da qual participaram massivamente intelectuais, artistas e escritores". (THIESSE, $2001 / 2002$ p. 7). Neste sentido, o primeiro elemento que exploramos é o da inexistência de naturalidade na nação, ou seja, as naçóes não são espontâneas, tratam-se antes de criaçóes históricas recentes (RENAN, 1997, p.162). As nações são por outro lado, constituídas através de um processo de construçóes políticas e simbólicas, do qual o sucesso resulta a existência da nação como externa a sua própria origem. A nação passa a existir por si só como algo além daquilo que lhe compóe, como um dado eterno e imutável. Neste sentido, Ernest Gellner adverte "é o nacionalismo que dá origem as nações, e não o contrário” (GELLNER, 1993, p. 89).

Por seu turno, Benedict Anderson propóe o entendimento da nação como uma comunidade política imaginada, que é imaginada à medida que seus membros não possuem contato direto uns com os outros, "embora todos tenham em mente a imagem viva da comunhão entre eles” (ANDERSON, 2008, p. 32). No campo de definiçóes dispostas pelo autor, ressalta-se: "[...] ela é imaginada como uma comunidade porque, independentemente da desigualdade e da exploração efetivas que possam existir dentro dela, a nação é sempre concebida como uma profunda camaradagem horizontal" (ANDERSON, 2008, p. 34). Ainda para o autor, são questóes importantes para o surgimento das consciências nacionais: a convergência do capitalismo e da tecnologia de imprensa que possibilitou a divulgação da língua vernácula impressa - sobretudo, com a ascensão de jornais e romances -, o que também permitiu a percepçáo de simultaneidade entre os membros de dada comunidade.

Para Gellner “o nacionalismo é uma teoria da legitimidade política que exige que as fronteiras étnicas não atravessem as fronteiras políticas” (GELLNER, 1993, p. 12). Em suma, a essência política, neste caso, é superior ao conteúdo étnico, ou seja, à 
medida que uma nação estabelece quem são os seus membros todos aqueles que não correspondem a este grupo deverão ser excluídos ou assimilados.

Portanto, o primeiro e mais relevante questionamento para entender a questão proposta neste trabalho é: o que define uma nação? Com base na reflexão clássica de Ernest Renan, o único princípio legítimo que rege a nação é a vontade. Renan refuta que as naçóes se originem de itens como dinastia, raça, língua, religiáo, interesses ou geografia e estabelece que "a essência de uma nação está em que todos os indivíduos tenham muito em comum, e também que todos tenham esquecido muitas coisas" (RENAN, 1997, p. 162). A naçáo, para Renan, tem suporte em um passado comum - composto tanto de lembranças gloriosas quanto de amnésias seletivas -, e em um presente marcado pelo consenso, ou seja:

Uma nação é, portanto, uma grande solidariedade, constituída pelo sentimento dos sacrifícios que se fizeram e que ainda se fariam. Ela supóe um passado, mas se resume no presente a um fato tangível: o consenso, o desejo claramente expresso de continuar a vida em comum. A existência de uma nação é (perdoem-me a metáfora) um plebiscito de todos os dias (RENAN, 1997, p. 174).

Por outro lado, Ernest Gellner acrescenta que os grupos não se mantêm unidos apenas pautados na vontade - entendida como lealdade, identificação e adesão voluntária -, mas sim através de dois pólos: a vontade e o medo. A coerção e o constrangimento assim como a vontade formam e sustentam o grupo. Neste sentido, em relação à esfera coercitiva Gellner expóe que:

Entre as várias sançôes implicadas pela manutenção da ordem, a mais radical de todas - a força - só pode ser aplicada por uma instituição social específica claramente identificada, bem centralizada e disciplinada. Essa instituição, ou conjunto de instituições, é o Estado. [...] [No entanto] existem Estados que carecem de vontade e meios para efetivarem o monopólio da violência legítima e que, apesar disso, continuam a ser, em muitos aspectos, "Estados" reconhecíveis (GELLNER, 1993, p. 14-15).

Daí o postulado do autor de que "o nacionalismo não se coloca para as sociedades sem Estado” (GELLNER, 1993, p. 15). O Estado não só detém o monopólio da violência e dessa forma os meios de coerção, como também é responsável por outras instituiçóes que funcionam como mecanismos de disciplina social, como é o caso das escolas.

Em relação às identidades nacionais Stuart Hall destaca que elas são formadas e transformadas através da representação (HALL, p. 50). Dessa forma, a nação, mais que uma entidade política é também "algo que produz sentidos - um sistema de representação cultural' (HALL, p.49, grifo no original). Com base no postulado de Hall da cultura nacional como um discurso, deve-se ressaltar que o estabelecimento daquilo que é nacional é um campo em disputa.

Desse modo, apresentadas as primeiras considerações, analisaremos a seguir a formulação da Doutrina de Segurança Nacional no Brasil e posteriormente serão expostos alguns elementos do processo de refundação nacional implantado a partir da década de 1970 . 


\section{ASPECTOS CONSTITUTIVOS DA DOUTRINA DE SEGURANÇA NACIONAL NO BRASIL}

A Doutrina de Segurança Nacional constituiu um conjunto teórico destinado a sustentar certa ordem político-social que visava assegurar o sistema econômico capitalista (WASSERMAN, 2004, p.27). Com origens em um cenário marcado pela Guerra Fria, a DSN incluiu concepçóes geopolíticas à sua base de argumentaçáo principalmente em relação à nação e a bipolaridade. No entanto, a geopolítica possuindo uma credibilidade maior e pretensões científicas não funcionou apenas como dispêndio da DSN, ao contrário, foi utilizada pela Doutrina para tentar estabelecer certo grau de confiabilidade em seu discurso (DOCKHORN, 2002, p. 33).

Com fundamento nos postulados geopolíticos, a nação era vista como um organismo que deveria se manter em constante expansão para sobreviver. A bipolaridade, por sua vez, seria apresentada como uma permanente divisão do mundo em duas partes, composta pelos EUA e a URSS (COMBLIN, 1978, p. 23). Joseph Comblin demonstra que, para os teóricos da segurança nacional as "naçóes estão reagrupadas em duas alianças opostas. Uma representa o bem e a outra o mal. A primeira se chama Ocidente e a outra Comunismo" (COMBLIN, 1978, p. 31). A América Latina, sob esse entendimento, integraria o bloco ocidental, portanto, deveria partilhar de sua luta contra anti-subversiva (anti-comunista).

Entre os elementos constitutivos da DSN estão: o conceito de guerra, o inimigo/ comunismo e a segurança nacional. Em relação ao conceito de guerra houve o alargamento do entendimento do conflito estritamente militar e limitado para o de guerra total e permanente. Tratava-se do desenvolvimento de uma visão de que o mundo estava em uma guerra absoluta e total contra o comunismo, e que por isso, toda a sociedade deveria ser incluída no conflito. Desse modo, a guerra seria ampliada:

\footnotetext{
Hoje ampliou-se o conceito de guerra [...] De guerra estritamente militar passou ela, a guerra total, tanto econômica e financeira e política e psicológica e científica como guerra de exércitos, esquadras e aviaçóes; de guerra total a guerra global; e de guerra global a guerra indivisível e por que náo reconhecê-lo? - permanente (COUTO E SILVA, 1967, p. 24).
}

Sobre isso Comblin postula que a guerra contemporânea se apresentava para a DSN na forma de Guerra Fria e, por sua condiçáo de guerra permanente travava-se em todos os planos: militar, político, econômico, psicológico (COMBLIN, 1978, p. 39). Assim:

[...] a guerra fria da Doutrina Truman forneceu uma chave para interpretar, daí por diante, tudo o que poderia acontecer no mundo. Cada vez que o status quo fosse questionado, em qualquer parte do mundo, cada vez que surgisse um governo desfavorável aos Estados Unidos, ou suscetível de tornar-se desfavorável, seria necessário ver nisso o espectro da guerra fria: a presença do dedo de Moscou (COMBLIN, 1978, p.40).

Ainda sobre o conceito de guerra, dois pontos adicionais foram integrados à versão latino-americana da DSN: o da guerra insurrecional e o da guerra revolucionária. A ameaça da subversáo podia manifestar-se, segundo os constructos da doutrina, tanto 
através da luta armada quanto a partir da oposição organizada (ALVES, 1984, p. 37). ${ }^{9}$ Desse modo:

Como a guerra revolucionária não é declarada e é promovida secretamente por forças externas do comunismo internacional, ela recruta seus combatentes entre a população do "país-alvo". Por definição, portanto, torna-se suspeita toda a população, constituída de "inimigos internos" potenciais que devem ser cuidadosamente controlados, perseguidos e eliminados (ALVES, 1984, p. 39).

Nesse cenário, houve a incorporação da importância da guerra indireta que determinou a criaçáo do "inimigo interno". O inimigo/outro na guerra convencional era o membro externo à nação, no entanto, dentro da ideia de guerra permanente ele foi deslocado de fora para dentro e passou a estar "infiltrado", ou seja, qualquer membro da sociedade poderia ser considerado inimigo. Assim, os teóricos da DSN latino-americanos estavam voltados ao:

[...] crescimento de movimentos sociais de classe trabalhadora, enfatizavam a ameaça da subversão interna e da guerra revolucionária. Além disso, a ideologia latino-americana de segurança nacional, especialmente em sua variante brasileira, volta-se especificamente para a ligação entre desenvolvimento econômico e segurança interna e externa (ALVES, 1984, p. 33).

O "inimigo interno" para a Doutrina poderia se manifestar dentro de: organizaçóes de esquerda, nos meios militares, nos sindicatos, em universidades e escolas, entre os jornalistas, ou seja, em qualquer tipo de organização política. A "estratégia de ação indireta" do comunismo agiria em duas frentes dentro da população, que eram assim compostas:

O público interno inclui militares da ativa e da reserva ou civis que trabalham em Ministérios militares, assim como a Polícia Militar e outras formas paramilitares. O público externo é composto de estudantes, líderes sindicais, meios de comunicação impressos e eletrônicos, grupos sociais influentes como os intelectuais, profissionais, artistas e membros de diferentes ordens religiosas. Esta classificação também inclui setores organizados da vida política e da sociedade civil, como organizaçóes de trabalhadores, estudantes e camponeses, além de clubes, associaçóes de bairro etc. (ALVES, 1984, p. 39).

Inserida na lógica do "inimigo interno" a segurança nacional traduzia-se em segurança interna. Dessa forma, duas estruturas foram essenciais para a operacionalidade da DSN, em primeiro lugar a construção de um sofisticado aparato repressivo "capaz de impor sua vontade e, se necessário, coagir a populaçáo” e em segundo lugar, o desenvolvimento de uma complexa rede de informações que permitiria a identificação dos infiltrados pela ação comunista indireta (ALVES, 1984, p. 41).

Neste sentido, não são os objetivos nacionais que exprimem a vontade nacional, mas é a necessidade de assegurar a sobrevivência da nação diante de uma "guerra total"

9 O Projeto Brasil Nunca Mais, através da análise de 695 processos políticos ( 7.367 nomes de réus) ocorridos entre os 1964 e 1979, demonstra que a maioria dos atingidos pela repressão eram jovens com idades iguais ou inferiores a 25 anos, de origem urbana, predominantemente de classe média e com grau universitário. Contudo, também houve registros de acusados provenientes de diversos setores sociais como: de organizaçóes de esquerda, militares (vinculados ao projeto nacionalista do governo deposto), sindicalistas, professores, estudantes, políticos, jornalistas e religiosos. Em relaçáo às acusaçóes o maior número de ocorrência foi a participação em entidades ou movimentos sociais e em menor grau a luta armada. (ARQUIDIOCESE de São Paulo, 1985, pp. 85-87). 
que define aquilo que deve ser protegido. Por outro lado, para a DSN a nação é "um ser de uma única vontade" e disso decorre que a vontade nacional é sobrevivência da nação frente ao comunismo (COMBLIN, 1978, p. 51). Em geral, os objetivos nacionais concentram-se em: integridade territorial; integridade nacional; democracia; progresso; paz social e soberania. A unidade entre esses elementos é o fato de estarem todos ameaçados pelo comunismo (COMBLIN, 1978, p. 53). No caso brasileiro figuram entre os "objetivos nacionais permanentes" expostos pelo General Golbery do Couto e Silva, os seguintes itens:

\begin{abstract}
Salvaguarda intransigente de nossa independência política, admitidas, embora, autolimitaçôes, nunca essenciais, da soberania nacional, em benefício da cooperação e da paz internacionais; - manutenção de um estilo de vida democrático, com bases cada vez mais amplas na participação efetiva e consciente do povo; [...]-consolidaçáo da unidade do grupo nacional, através de crescente integração social, com fundamentação nos princípios da justiça social e da moral cristâ; -a incorporação efetiva de todo o território nacional [...]; -o fortalecimento equilibrado da estrutura econômica, de modo a assegurar elevados níveis de bem-estar e cultura a todo o povo, em tôdas as regióes do país, e garantindo-se o grau de auto-suficiência realmente indispensável ao pleno exercício da própria soberania nacional; -a manutenção do status quo territorial na América do Sul, contra quaisquer tendências revisionistas ou a formação de blocos regionais, políticos ou simplesmente econômicos, que possam vir a constituir ameaça à própria paz do continente; -o robustecimento da solidariedade e cooperação entre os povos da América, para o progresso geral e a defesa continental; -o fortalecimento do prestígio nacional no âmbito externo, com base no princípio da igualdade jurídica dos Estados, e a crescente projeção do país no exterior com vias à salvaguarda eficaz de seus próprios interesses em benefício também da própria paz internacional. (COUTO E SILVA, 1967, pp. 74-75).
\end{abstract}

Devemos analisar a imprecisáo em que os termos são postos e o impacto decorrente no campo de ação que a segurança nacional desenvolve. Em primeiro lugar, a salvaguarda da independência política com a ressalva de possíveis "autolimitaçóes" em virtude da cooperação e paz internacionais, pode indicar a subordinação aos centros de poder, pois, se para Golbery geopoliticamente o Brasil é componente do Ocidente e está por excelência ao lado dos Estados Unidos, em dado momento pode estar subordinado a este desde que isso implique na manutenção da "cooperação" entre os dois países. Portanto, justifica ao mesmo tempo, uma lógica de desenvolvimento dependente e uma subordinação política. Em segundo lugar evoca-se a manutenção de um estilo de vida democrático e não da democracia em si, o que demonstra a vinculação desse discurso a um regime autoritário.

Em "o robustecimento da solidariedade e cooperação entre os povos da América, para o progresso geral e a defesa continental" pode-se deduzir que se trata da defesa continental frente à ameaça comunista. A proposiçáo acerca do progresso como oposto ao comunismo tomou força a partir da integraçáo da ideia de desenvolvimento como instrumento de combate ao comunismo, terminando por integrar a partir de 1967, no Brasil, a Doutrina de Segurança Nacional e Desenvolvimento.

A vagueza no conteúdo dos objetivos nacionais corresponde a um movimento intencional, que visa, grosso modo, incorporar uma série de grupos sociais diferentes ao redor de um "objetivo em comum": a segurança da nação frente à ameaça comunista. A imprecisão do que efetivamente correspondia a DSN possibilitava sua aplicação irrestrita como 
fundamento às ações repressivas dos regimes ditatoriais do Cone Sul. Portanto, o único componente que deveria ser preciso dentro das formulaçóes da DSN era a delimitação do outro, o "inimigo", pois, sem ela não havia um conteúdo próprio ou objetivos claros. A este respeito Comblin destaca que:

O conceito de segurança nacional tornou-se muito operacional desde o momento em que se define o inimigo. A segurança nacional talvez não saiba muito bem o que está defendendo, mas sabe muito bem contra quem: o comunismo. (COMBLIN, 1978, p. 55).

No caso latino-americano, houve também a incorporação da importância da guerra indireta que determinou a criação do "inimigo interno". O inimigo/outro se desloca do membro externo a nação e passa a estar "infiltrado" dentro da própria nação, com isso, qualquer membro da sociedade poderia ser considerado o inimigo. Nesta perspectiva os teóricos da ideologia de segurança nacional latino-americanos estavam voltados ao:

Crescimento de movimentos sociais de classe trabalhadora, enfatizavam a ameaça da subversão interna e da guerra revolucionária. Além disso, a ideologia latino-americana de segurança nacional, especialmente em sua variante brasileira, volta-se especificamente para a ligação entre desenvolvimento econômico e segurança interna e externa (ALVES, 1989, p. 33).

Desse modo, a segurança nacional surge como instrumento da nação para defender-se da ameaça comunista, trata-se da aplicação da força de Estado para garantir sua sobrevivência, neste sentido, a segurança nacional nas trilhas da DSN é:

A capacidade que o Estado dá a Nação para impor seus objetivos a todas as forças oponentes. [...]. Trata-se, portanto da força do Estado, capaz de derrotar todas as forças adversas e de fazer triunfar os Objetivos Nacionais. [...] A segurança nacional é a força do Estado presente em todos os lugares em que haja suspeita do fantasma do comunismo (COMBLIN, 1978, pp. 54-55, grifo nosso).

Portanto, nota-se a utilização do conceito de nação pela DSN para a criação de duas ideias: o de que as naçóes seriam um corpo coeso e homogêneo e o de que a sobrevivência do comunismo representaria um perigo constante às naçóes aliadas geopoliticamente ao Ocidente. Daí a importância dos dois conceitos emprestados da geopolítica: de nação e de bipolaridade.

A criação da concepçáo de um consenso social a respeito dos objetivos da nação era necessária à justificativa de aplicação da segurança nacional, portanto, Comblin expóe que para base teórica da Doutrina: "a nação é vista como um todo homogêneo e dotado de uma única vontade: a partir daí pode-se facilmente deduzir a ideia de interesse nacional, [...] todos os conflitos sociais desaparecem, assim como todos os problemas da política interna” (COMBLIN, Op. cit., p. 29). A vontade passa a ser impulsionadora para a Doutrina a partir do movimento discursivo que personifica a naçáo como uma entidade. A nação dentro das linhas da DSN é: "a única vontade, um único projeto: ela é o desejo de ocupação e de domínio do espaço [...] ela é desejo de poder” (COMBLIN, 1978, p. 28).

Considerando as proposiçóes da DSN pode-se perceber que a base de sua argumentação se dá justamente na concepção da nação como existente a priori. Para nossa reflexão, a nação é resultado de uma série de construções políticas e simbólicas, dessa forma, entende-se 
que o proposto pela DSN não se trata da manifestação de uma vontade nacional, mas está relacionada ao seu processo de criação. Neste sentido, como em uma câmara escura as imagens encontram-se invertidas, a segurança nacional surge como destinada a proteger a nação, no entanto, ela é produto da ideia da nação criada pela DSN.

\section{DESDOBRAMENTOS DA DOUTRINA DE SEGURANÇA NACIONAL}

Após a vitória do discurso sobre a nação da DSN, levada a efeito através do golpe civil-militar, o Brasil passou por um processo de "refundação nacional", em que os símbolos anteriormente construídos como nacionais foram revisitados e reformulados para atender a necessidade de legitimação do regime ditatorial estabelecido. A ideia de nação postulada pela DSN no período anterior ao golpe precisava de certo conteúdo simbólico e material. A questão das comemorações e até mesmo da criação de novas festas cívicas podem ser consideradas resultados dessa demanda. Neste sentido retomase o proposto por Hall de que "as pessoas não são apenas cidadãos/ãs legais de uma nação; elas participam da idéia de nação tal como representada em sua cultura nacional" (HALL, p.49, grifo no original).

Assim como o primeiro movimento no século XIX, de construção de identidades nacionais, contou com grupos que articularam sua criação, podemos apontar o esforço constante de alguns intelectuais vinculados à DSN de criar uma nova ideia de nação. Para ilustrar esse movimento, apresentaremos uma breve análise de mudanças ocorridas no Brasil.

No Brasil, podemos elencar dois momentos importantes para nossa argumentaçáo: o primeiro no início da década de 1960, marcado pela disputa discursiva sobre o que era efetivamente nacional e o segundo após o golpe quando se busca realizar uma refundação nacional. Um bom exemplo acerca da primeira fase em que imperava a disputa entre dois projetos nacionalistas é o livro de André Gama "Nossos males e seus remédios". ${ }^{10}$ Nele encontramos uma crítica ao nacionalismo de orientação populista, ${ }^{11}$ sua argumentação parte da visão do projeto nacionalista formulado pelo IPES/IBAD/ ESG:

O nacionalismo é próprio das colônias que desejam a sua independência. Tiradentes era nacionalista. Lutava contra os impostos e o ouro que eram mandados daqui para Portugal. Ele achava que isto devia permanecer aqui para melhorar as condiçóes de vida dos brasileiros. [...]. Por isso Tiradentes é nosso herói nacional. Mas quando o Brasil se tornou independente há 140 anos passados, tudo aquilo acabou. [...] O nacionalismo que apareceu recentemente entre nós é ódio de tudo que não é brasileiro. É uma doença muito feia e impatriótica, porque odiar os outros não nos faz bem nenhum. Só nos faz mal. É simplesmente uma das armas usadas para implantar o comunismo no Brasil. [...] A máscara nacionalista pretende negar a estrangeiros

\footnotetext{
$10 \quad$ O livro contou com 103.000 exemplares e compõe uma série de publicaçôes financiadas pelo Instituto de Pesquisas e Estudos Sociais (IPES) que visava disseminar conteúdo anticomunista. Eram públicos a quem se destinava: Colégios secundários e superiores; empresas, sindicatos de trabalhadores "democráticos"; associaçóes religiosas e civis e particulares (GAMA, 1963).

11 Destacado pelo autor como comunista.
} 
a exploração de nossas riquezas naturais e dos serviços públicos. [...] Precisamos do capital estrangeiro e é um crime impedi-lo de ajudar-nos. Não quero dizer que todos os nacionalistas sejam comunistas, porque isto não seria verdade. Mas é verdade que os comunistas pregam o nacionalismo para prolongar a nossa pobreza, aumentar o nosso desespero e facilitar a revolução comunista. (GAMA, 1963, pp. 35-36).

Esse texto corresponde a uma série de publicaçóes realizadas pelo IPES, durante o início da década de 1960, que objetivavam a divulgação das premissas da segurança nacional, bem como, a desestabilização do governo de João Goulart (1961-1964). ${ }^{12}$ Note-se uma aparente rejeição ao nacionalismo de tipo libertário. $\mathrm{O}$ capital estrangeiro é trazido como solução aos problemas do desenvolvimento da nação, por isso, qualquer nacionalismo que vise o seu impedimento é representado como comunista. Neste sentido, para esse discurso o "capital estrangeiro" não apresenta perigo algum e a nação só pode ser espoliada pelo comunismo.

A respeito do segundo momento a partir de 1964, o discurso nacionalista baseado na DSN torna-se vitorioso, ocorre então o retorno a um passado nacional em busca de elementos que possam constituir uma nova cultura nacional. Neste cenário, as festividades tornam-se componentes simbólicos essenciais. Um exemplo disso são os eventos realizados no Brasil no ano de 1972, em meio à comemoração dos 150 anos da Independência. Primeiramente houve o traslado dos restos mortais de D. Pedro I, que como dispóe Janaína Cordeiro, representava o retorno à Pátria de seu grande herói: ${ }^{13}$

O retorno de seu primeiro Imperador parecia evidenciar a força e o vigor de um país que se preparava para o início das comemoraçóes dos 150 anos de sua Independência. De um lado do oceano, portanto, a partida do rei, a decadência do governo e a indiferença da sociedade. De outro, a volta do Imperador, o poder do governo e uma sociedade que comemorava o fato de estar vivendo um verdadeiro milagre, o Milagre Brasileiro. De um lado, um velório sombrio e enlutado. De outro, também um velório, porém emocionado, cívico, que cantava com orgulho seu passado, com confiança o seu presente e com otimismo seu futuro. Enfim, um velório que cantava a Pátria e o retorno de seu grande herói. (CORDEIRO, 2012, p. 65, grifo no original).

Existe uma referência clara ao momento que se representa como de fundação inicial da nação, que neste caso é tido como a Independência do Brasil. As comemoraçóes do ano de 1972 tendem a fazer alusão entre os dois eventos, a Independência como primeiro momento fundador e o Sesquicentenário como segundo, trata-se do projeto de refundação nacional. Note-se neste ponto que era necessário reforçar o passado comum nacional, seus heróis e datas de comemoração cívica (Tiradentes, Independência, Proclamação da República). Até mesmo a sequência das datas em meio à comemoração do sesquicentenário tem uma lógica própria: inicia-se em 21 de abril e termina em 7 de setembro, com isso objetivava-se "uma associação entre as figuras de Tiradentes e D.

12 Não nos deteremos mais nesse ponto devido a discussão sobre a primeira fase de disputa discursiva ultrapassar os objetivos estabelecidos para este trabalho.

13 Como postulado por José Murilo de Carvalho: "Heróis são símbolos poderosos, encarnaçóes de idéias e aspiraçôes, pontos de referência, fulcros de identificação coletiva. São, por isso, eficazes para atingir a cabeça e o coração dos cidadãos a serviço da legitimação de regimes políticos" (CARVALHO, 1990, p. 55). 
Pedro I" (CORDEIRO, 2012, p.100). Esse movimento corresponde ao estabelecimento de uma linha de continuidade, em que a nação, seria resultado de uma evolução natural, que a conduz rumo ao progresso.

Como aponta José Murilo de Carvalho os governos militares estabeleceram através de lei em 1965, “Tiradentes como patrono cívico da nação brasileira”, bem como a obrigatoriedade de colocar seus retratos em todas as repartiçóes públicas (CARVALHO, 1990, p. 71). Justamente há o estabelecimento de um culto cívico às figuras consagradas como nacionais.

No momento em que imperam as disputas sobre o que é nacional sobressai-se a questão do inimigo, da necessidade de proteger a nação do outro/comunismo. Desse modo, existe apenas uma vontade no presente de que a nação sobreviva e isso é posto como justificativa para o estabelecimento de uma política de guerra.

Porém a necessidade de criar consenso social após o estabelecimento da Ditadura de Segurança Nacional resulta na construção de um todo simbólico em que os elementos constituídos como nacionais são revisitados. Segue-se disso que a apropriação sobre o que é nacional ocorre em favor da manutenção de dada ordem política. Neste sentido, cabe ainda ressaltar que a utilização da força simbólica do herói nacional não se restringia apenas ao regime, sua imagem também foi apropriada pelos opositores da ditadura (Ibid.).

O que ocorre é a necessidade da formação de novos cidadãos e a consequente legitimação dos regimes ditatoriais como defensores da nação. Trata-se da formação da juventude que estava crescendo em meio ao regime ditatorial, diferente daquela da década de 1960 componentes de uma geração "influenciada pelo comunismo", ou seja, uma nova cultura nacional deveria ser construída com referentes alternativos ao que tinha sido a cultura da década de 1960 (MARCHESI, 2011, p. 571). Esse movimento reflete a busca em um passado imemorial de elementos que deem sentido e que renovem o pertencimento dos indivíduos à nação e, mais que isso, que permitam delimitar o indivíduo que é membro da nação que participa de todas essas construçóes simbólicas e o não membro, aquele que possui uma "ideologia" considerada de fora.

De toda forma, trata-se de um processo de formação social, seguido de adequaçóes disciplinares, que tinham por objetivo que todos os indivíduos fossem enquadrados em um modelo idealizado de nação. Retomando o conteúdo exposto por Comblin ${ }^{14}$, sobre um dos objetivos nacionais brasileiros, o de "integridade nacional", pode-se extrair a seguinte definição:

Consolidar toda a comunidade nacional (língua, ascensão moral, mistura racial e supressáo das desigualdades sociais) graças a um espírito de solidariedade crescente entre todos os seus membros, sem preconceitos de qualquer natureza, com uma participação consciente e ativa no esforço comum para preservar os valores que caracterizam a personalidade cultural brasileira, tradicionalmente cristá (COMBLIN, 1978, p.51).

14 Comblin aponta para o resumo dos objetivos nacionais elaborado por José Alfredo Gurgel. 
Quando evoca o "espírito de solidariedade crescente entre todos os seus membros" tem-se subliminarmente a questão da vontade, do consenso já esboçado por Ernest Renan. Entretanto, isso aparece aqui como uma tentativa de homogeneizaçáo dos membros da nação e reforça a ideia de vontade nacional presente na DSN.

O que extraímos da experiência da Ditadura de Segurança Nacional brasileira é a questão do processo constitutivo do que é concebido como naçáo. O nacionalismo apresenta novamente seu aspecto político, a ideia nação é construída a partir de um discurso que a precede. No primeiro momento, a DSN estabelece uma ideia de naçáo que é a base dos postulados da segurança nacional e no segundo momento é atribuído um conteúdo a essa ideia, ambos os momentos correspondem a uma série de construçóes políticas e simbólicas, o que nos demonstra a inexistência de naturalidade na ideia de nação proposta pela DSN.

\section{CONSIDERAÇÕES FINAIS}

A nação é apresentada como um ser, um organismo constituído e acabado, dotado de vontade. Dessa forma, a segurança nacional surge como instrumento para assegurar a sobrevivência da nação. No entanto, essa é uma falsa realidade à medida que a nação não existe por si só, ela é uma construção política e cultural. Sendo assim, qualquer determinação que exprima a vontade nacional como espontânea não é mais que um recorte dos interesses de um ou mais setores sociais, mas que náo correspondem ao todo. A base argumentativa da Doutrina de Segurança Nacional está pautada na concepção da nação como existente a priori, como algo eterno e imutável.

A maneira pela qual o projeto de exaltação daquilo que se postulava como nacional obteve sucesso, foi justamente através da dupla determinaçáo entre a vontade e o medo. Se por um lado, o passado nacional era revigorado e resinificado para legitimar os regimes ditatoriais, fazendo referência a um passado comum e a vontade nacional, por outro lado através da normatividade escolar e da repressáo se excluíam todos aqueles que estivessem fora deste projeto, fazendo imperar assim o medo como constitutivo do grupo social. Neste sentido, o que melhor define a nação nestes casos é o postulado de Gellner, em que a unidade do grupo se dá justamente pela junção da lealdade, identificação e adesão voluntária a coerção e ao constrangimento.

A Doutrina de Segurança Nacional forneceu a base teórico-ideológica aos regimes repressivos estabelecidos no Cone Sul na segunda metade do século XX e também conferiu o alicerce necessário ao estabelecimento de um novo tipo de identidade nacional a esses países. A apropriação de símbolos constituídos como nacionais é recorrente em diversos momentos históricos e se trata por excelência de uma atividade política. $\mathrm{O}$ nacionalismo corresponde à disputa discursiva em que o projeto que obtém sucesso delimita o que é concebido como nação.

Por fim, buscou-se realizar uma exposição acerca de como se deu a relação entre a ideia de nação e a segurança nacional, seguida de exemplos do processo denominado 
como "refundação nacional", porém, não se puderam examinar aqui todas as manifestaçóes desse processo nos países do Cone Sul. Portanto, este trabalho não exclui futuras abordagens dessa temática, e constitui por outro lado, uma breve análise das circunstâncias em que foi construído o discurso da segurança nacional pautado na Guerra Fria. 


\section{REFERÊNCIAS}

ALVES, Maria Helena Moreira. Estado e Oposição no Brasil (1964-1984). 5. Ed. Petrópolis: Vozes. 1989.

ANDERSON, Benedict R. Comunidades Imaginadas: reflexões sobre a origem e a difusão do nacionalismo. São Paulo: Companhia das Letras, 2008.

ARQUIDIOCESE de São Paulo. Brasil: nunca mais. Petrópolis: Vozes, 1985.

CARVALHO, José Murilo de. Tiradentes: um herói para República. In: A formação das Almas. O imaginário da república no Brasil. 5ª reimpressão. São Paulo: Companhia das Letras, 1998. pp. 55-73.

COUTO E SILVA, Golbery do. Geopolítica do Brasil. 2a ed. Rio de Janeiro: José Olympio Editora, 1967.

COMBLIN, Joseph. A Ideologia da Segurança Nacional: O Poder Militar na América Latina. 2. ed. Rio de Janeiro: Civilização Brasileira, 1978.

CORDEIRO, Janaina Martins. Lembrar o passado, festejar o presente: as comemoraçóes do Sesquicentenário da Independência entre consenso e consentimento (1972). Tese (doutorado). Rio de Janeiro: UFF, 2012.

DOCKHORN, Gilvan Veiga. Quando a ordem é segurança e o progresso é desenvolvimento (1964-1974). Porto Alegre: EDIPUCRS, 2002.

DREIFUSS, René Armand. 1964 A conquista do Estado: Ação Política, Poder e Golpe de Classe. Petrópolis: Vozes, 1981.

GAMA, André. Nossos Males e seus Remédios. 7a ed. Petrópolis: Editora Vozes Ltda, 1963.

GELLNER, Ernest. Definiçóes; Que é uma nação? In: Naçóes e Nacionalismo. Lisboa: Gradiva, 1993. pp. 11-20 e 85-98.

HALL, Stuart. A Identidade Cultural na Pós-Modernidade. $4^{\mathrm{a}}$ ed. Rio de Janeiro: DP\&A, 2000. pp. 47-65.

HOBSBAWM, Eric J.. Era dos extremos: o breve século XX: 1914-1991. São Paulo: Companhia das Letras, 1995.

. Naçóes e Nacionalismos desde 1780: Programa, mito e realidade. Rio de Janeiro: Paz e Terra, 1990.

MARCHESI, Aldo. Uma parte do povo uruguaio feliz, contente alegre: os caminhos culturais do consenso autoritário durante a ditadura. Trad. Maria Brum In: ROLLEMBERG, Denise; QUADRAT, Samantha (orgs.). A construçáo social dos regimes autoritários: Brasil e América Latina, volume II. Rio de Janeiro: Civilização Brasileira, 2011. pp. 565-595.

PADRÓS, Enrique Serra. Como el Uruguay no hay...Terror de Estado e Segurança Nacional Uruguai (1968-1985): do Pachecato à Ditadura Civil-Militar. Tomo I. Tese de 
Doutorado. Porto Alegre: UFRGS, 2005.

(org.) Cone Sul em tempos de ditadura: reflexôes e debates sobre a História

Recente. Porto Alegre: Evangraf/UFRGS, 2013.

PÉCAUT, Daniel. Os Intelectuais e a Política no Brasil: Entre o Povo e a Nação. São Paulo: Editora Ática, 1990.

RAMOS, Plínio de Abreu. Como Agem os Grupos de Pressão? Cadernos do Povo Brasileiro, v. 20, Rio de Janeiro: Civilização Brasileira, 1963.

RENAN, Ernest. ¿Qué es una nación? In: FERNÁNDEZ BRAVO, Álvaro (comp.). La invención de la Nación. Buenos Aires: Manantial, 2000. pp.

THIESSE, Anne-Marie. Ficções Criadoras: as Identidades Nacionais. Anos 90. Porto Alegre, n.15, 2001/2002.

WASSERMAN, Cláudia. O império da Segurança Nacional: o golpe de 1964 no Brasil. In: WASSERMAN, Cláudia; GUAZZELLI, César A. B. (Orgs.). Ditaduras Militares na América Latina. Porto Alegre: Editora da UFRGS, 2004. pp. 27-44.

Recebido: 22/6/2017

Aceito: 2/10/2017 